\title{
Atorvastatin Attenuates Bone Loss and Aortic Valve Atheroma in $\mathrm{LDLR}^{-/-}$Mice
}

\author{
Nalini M. Rajamannan ${ }^{a, b}$

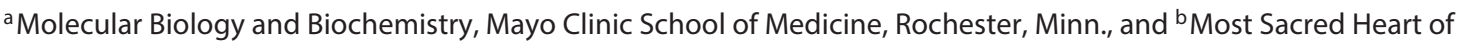 \\ Jesus Cardiology and Valvular Institute, Sheboygan, Wis., USA
}

For editorial comment see p. 9

\section{Key Words}

Atherosclerosis · Lipids · Osteoporosis

\begin{abstract}
Atherosclerosis and osteoporosis are the leading causes of mortality and morbidity. The objective of this study was to test this hypothesis in experimental hypercholesterolemia to determine whether statins play a protective role in this process. $\mathrm{LDLR}^{-/-}$mice $(\mathrm{n}=60)$ were allocated to the following groups: group I $(n=20)$, normal diet; group II $(n=20)$, $0.25 \%(w / w)$ cholesterol diet $(w / w)$, and group III $(n=20)$, $0.25 \%(\mathrm{w} / \mathrm{w})$ cholesterol diet + atorvastatin for 48 weeks. Examination of aortic valves (AVA) and femurs for atherosclerosis and calcification markers included micro-CT, special stains, and calcein incorporation. The cholesterol diet induced bone formation in calcified AVA and an increase in macrophage infiltration. Hyperlipidemic bones expressed an increase in osteoclast cells and a decrease in bone formation. Atorvastatin reduced atherosclerosis and bone mineralization in AVA and increased mineralization within femur bones $(p<0.05)$. Atherosclerosis is present in hyperlipidemic bones and valves as characterized by macrophage and osteoclast infiltration, and it is attenuated by atorvastatin, which may have implications for therapy in the future.
\end{abstract}

(c) 2015 The Author(s)

Published by S. Karger AG, Basel

\begin{tabular}{ll}
\hline KARGER 125/s & Co 2015 The Author(s) \\
& Published by S. Karger AG, Basel \\
& $0008-6312 / 15 / 1321-0011 \$ 39.50 / 0$ \\
E-Mail karger@karger.com & This article is licensed under the Creative Commons Attribution- \\
www.karger.com/crd & NonCommercial-NoDerivatives 4.0 International License (CC BY- \\
& NC-ND) (http://www.karger.com/Services/OpenAccessLicense). \\
& Usage and distribution for commercial purposes as well as any dis- \\
tribution of modified material requires written permission.
\end{tabular}

\section{Introduction}

Atherosclerosis and osteoporosis are common medical conditions that are increasing in prevalence as the population ages throughout the world. Recent studies have demonstrated parallel risk factors for the development of these disease processes; however, the phenotypic expression of these diseases has masked our understanding of the initiating events that are critical in these disease processes. Atherosclerosis is characterized as a complex inflammatory disease that develops secondary to risk factors such as elevated cholesterol, diabetes, and hypertension in smoking males and postmenopausal women [1]. This disease continues to be the primary cause of death in the world. The initial lesion has been characterized as a fatty streak lesion that represents a complex series of signaling events and inflammatory cells accumulating along the vascular and valvular surfaces. Osteoporosis is also a complex inflammatory disease that develops secondary to similar risk factors including hypercholesterolemia, postmenopausal status, age, smoking, diabetes, and phosphorus levels $[1,2]$. This disease continues to be the leading cause of bone fractures in postmenopausal women, leading to a high morbidity and mortality [1]. There is increasing evidence that both of these disease processes develop in parallel in patients, with a phenotype of decreased bone formation in bones and increased bone formation in the cardiovascular system [1]. For years, lipids

Nalini M. Rajamannan, MD

Visiting Scientist, Mayo Clinic 200 First St SW

Rochester, MN 55905 (USA)

E-Mail nrajamannan@gmail.com 

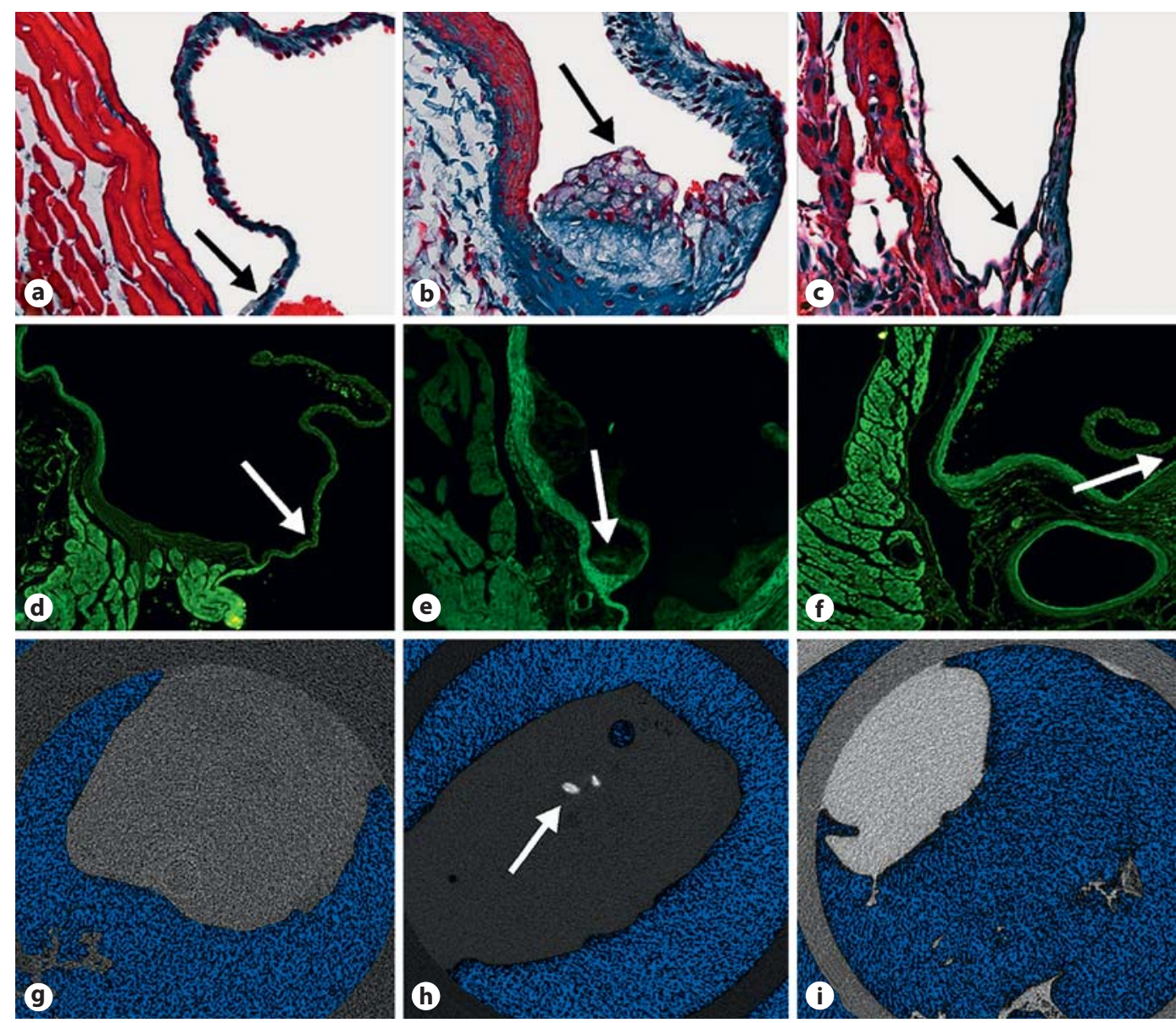

Fig. 1. a-c Masson's trichrome staining of the AVA. a Control. b Cholesterol. c Atorvastatin + cholesterol (the arrows point to AVA). d-f Calcein incorporation in the AVA. d Control. e Cholesterol. $\mathbf{f}$ Atorvastatin + cholesterol (the arrows point to AVA). g-i Micro-CT of the AVA. g Control. h Cholesterol. i Atorvastatin + cholesterol (the arrow points to the calcified AVA).

have been hypothesized as a mechanism of both disease processes, but the cellular processes are not well known. This short report tests whether there is an increase in mineralization in the heart and a decrease in the skeleton, using an experimental hypercholesterolemic LDLR $^{-/}$ mouse model with and without atorvastatin.

\section{Methods}

$L D L R^{-/-}$Experimental Hypercholesterolemia Mouse Model

$\mathrm{LDLR}^{-1-}$ mice aged 6-8 weeks were purchased from Jackson Laboratories (Bar Harbor, Maine, USA). The mice were assigned to a control group $(\mathrm{n}=60)$, a $0.2 \%(\mathrm{w} / \mathrm{w})$ cholesterol diet (Harlan Teklad 88137; $\mathrm{n}=60)$, or a $0.2 \%(\mathrm{w} / \mathrm{w})$ cholesterol diet (Harlan Teklad 88137$)$ plus $0.1 \%(\mathrm{v} / \mathrm{v})$ atorvastatin in drinking water $(\mathrm{n}=$ 60). All animals were fed ad libitum for 23 weeks. Control mice were fed a standard diet. Following this 20 -week period, the mice were euthanized via inhalation of $\mathrm{CO}_{2}$. All experiments were performed in an animal facility accredited by the Association for Assessment and Accreditation of Laboratory Animal Care, Inc. (ACUC-A3283-01, 1-08-382). Hearts and femurs were removed and placed in $100 \%$ ethanol for bone histomorphometry and microCT analysis. Paraffin-embedded sections $(6 \mu \mathrm{m})$ were cut and prepped for histopathologic examinations using Masson's trichrome stain in valves and Goldner's stain in femurs. Fluorescence microscopy was used to assess the presence of calcein incorporation.

\section{Microcomputed Tomography}

Valves and femurs were examined using a Scanco MicroCT-40 system operated at $45 \mathrm{kV}$. Sampling was done with $\sim 8-\mu \mathrm{m}$ voxels (volume elements) and maximum sensitivity (1,000 projections, 2,048 samples, and $0.3 \mathrm{~s} /$ projection integration [3]). Sixty valves and 60 femurs were tested in total. Micro-CT is essentially a highresolution version of clinical CT for smaller samples. After recording a set of slices of the valve and femur tissue, the total amount of 

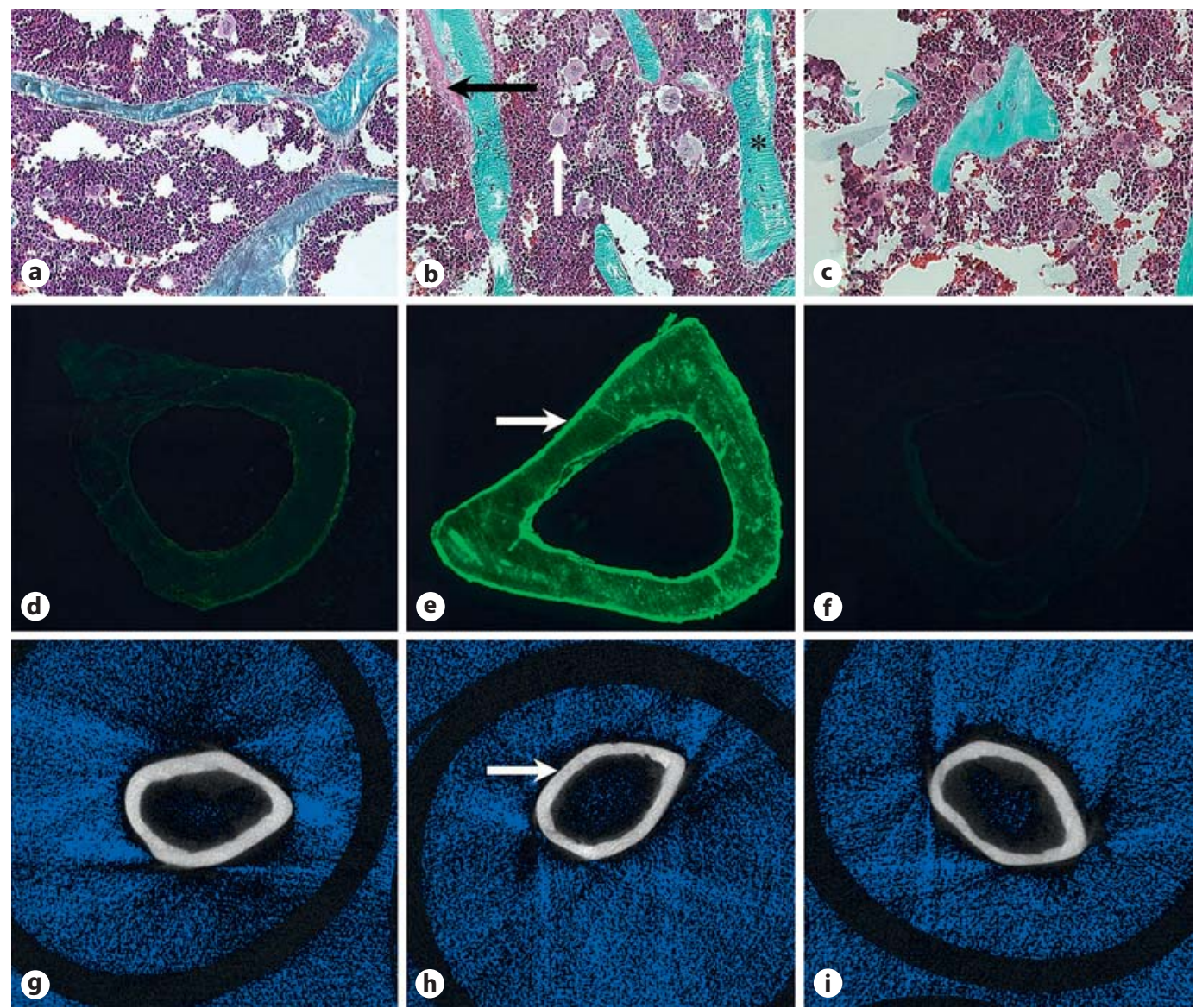

Fig. 2. a-c Goldner's stain of the femur. a Control. b Cholesterol. c Atorvastatin + cholesterol (the black arrow points to the increased bone turnover, and the white arrow points to osteoclast cells). $\mathbf{d}-\mathbf{f}$ Calcein incorporation in the femur. $\mathbf{d}$ Control. e Cholesterol. $\mathbf{f}$ Atorvastatin + cholesterol (the white arrow points to an increase in calcein uptake, indicating an increase in bone turnover in hypercholesterolemic femurs). g-i Micro-CT of the femur. g Control. $\mathbf{h}$ Cholesterol. i Atorvastatin + cholesterol (the white arrow points to the decreased bone thickness in the hypercholesterolemic bone).

mineralized tissue and the fraction of tissue mineralized in the sample were determined using techniques employed in earlier valve studies $[4,5]$. One threshold was used for the total tissue and a second for the mineralized tissue, and the necessary computations were performed using the Scanco system's software suite. The microstructure of the mineralized valve tissue was characterized; relationships with the different treatment groups were measured. ANOVA statistical analysis was performed to test differences in the different treatment groups ( $\mathrm{p}<0.05$ was considered statistically significant).

\section{Results}

To understand whether $\mathrm{LDLR}^{-/-}$mice develop atherosclerosis in bone and osteoporosis in valves via cholesterol, $\mathrm{LDLR}^{-/-}$mice were given a cholesterol diet versus cholesterol and atorvastatin. Figure 1 demonstrates the characterization of the aortic valve (AVA) phenotype as defined by histology, calcein, and micro-CT. Figure la-c shows the histology of AVA, and figure $1 \mathrm{~d}-\mathrm{f}$ shows confocal microscopy used to detect the presence of calcein incorporation. Figure 1g-i shows the micro-CT of AVA from these mice, demonstrating increased calcification in the valves as compared to atorvastatin treatments. Figure 2 demonstrates the characterization of the femur phenotype as defined by histology, calcein, and micro-CT. Figure $2 \mathrm{a}-\mathrm{c}$ shows the histology of the femurs, and figure $2 \mathrm{~d}-\mathrm{f}$ shows confocal microscopy to detect the presence of calcein incorporation, which demonstrates an increase in calcein incorporation in the cholesterol femurs and a decrease with atorvastatin treatment. Figure $2 \mathrm{~g}-\mathrm{i}$ is a micro- 


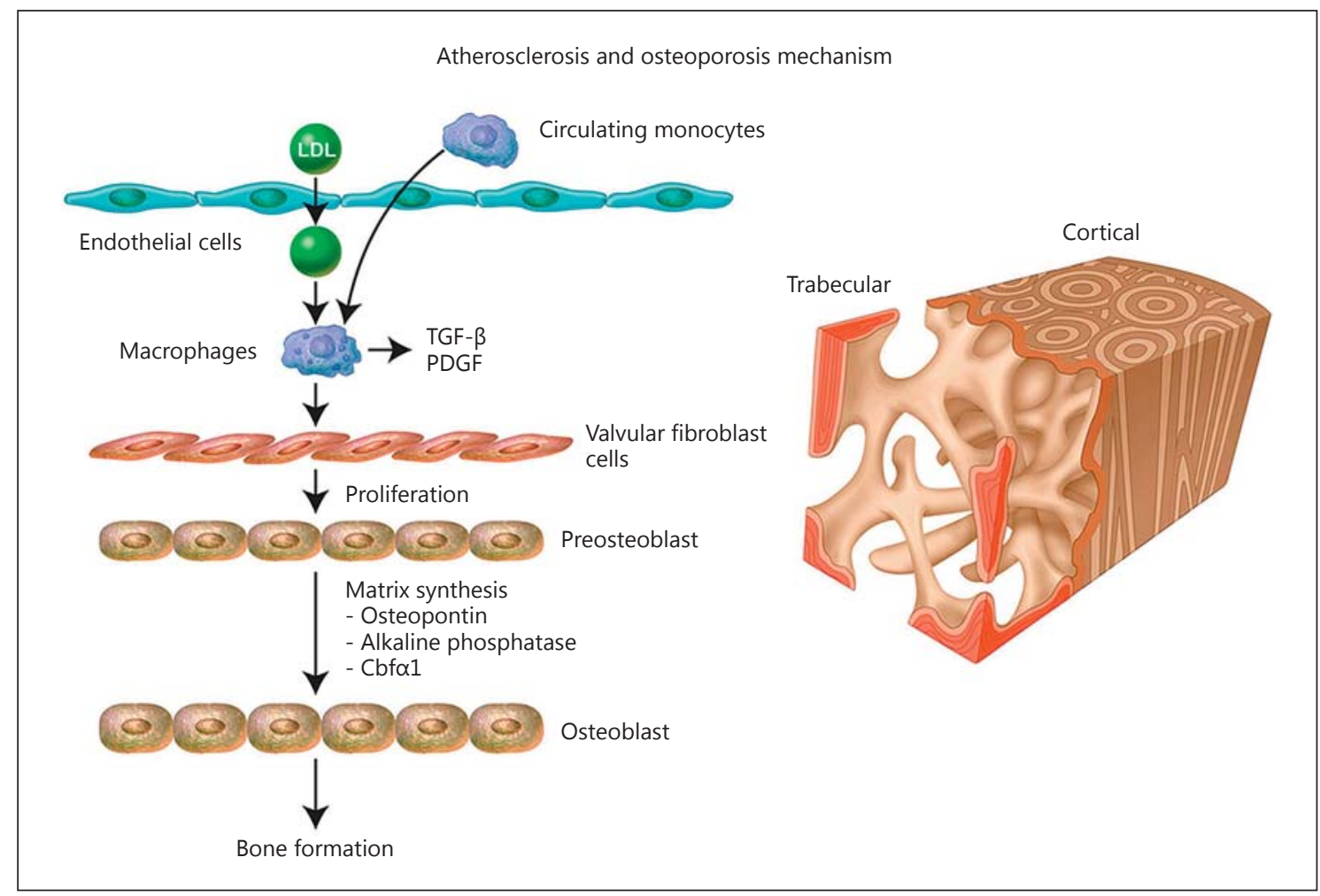

Fig. 3. Mechanism of elevated lipids in the valve and in the bone, causing inflammation and atherosclerosis in the valve and osteogenic bone turnover and decreased bone formation in the femur. Cbfal = Core-binding factor subunit $\alpha-1$.

Table 1. Quantification of micro-CT of $\mathrm{LDLR}^{-/-}$hearts and femurs from mice on 3 different diets

\begin{tabular}{lccc}
\hline & Control & Cholesterol & $\begin{array}{l}\text { Cholesterol }+ \\
\text { atorvastatin }\end{array}$ \\
\hline $\begin{array}{c}\text { Heart } \\
\text { Micro-CT }\end{array}$ & $0.019 \pm 0.033$ & $0.092 \pm 0.065^{*}$ & $0.048 \pm 0.052^{* *}$ \\
$\begin{array}{c}\text { Femur } \\
\text { Micro-CT }\end{array}$ & $4.78 \pm 0.040$ & $4.70 \pm 0.036^{*}$ & $4.75 \pm 0.036^{* *}$ \\
\hline
\end{tabular}

* Control as compared to cholesterol; ** cholesterol as compared to cholesterol + atorvastatin.

CT of the femurs of $\mathrm{LDLR}^{-/-}$mice on different diets, demonstrating a decrease in thickness and bone mineral content in the cholesterol group compared to control and atorvastatin mice. These results indicate that the there is a decrease in bone thickness as measured by micro-CT in the presence of hypercholesterolemia. Table 1 displays the quantification of the mineral content in valves and femurs.

\section{Discussion}

Cardiovascular calcification and osteoporosis are the most common causes of morbidity and mortality in the USA. The spectrum of degenerative valve lesions has traditionally been thought to be due to a passive disease process developing rapidly within the valve leaflets. The most common location of calcific AVA disease is the left side of the heart $[6,7]$. Recently, the biology of the heart valve has changed from a concept of degeneration to an active biologic disease process [8]. Moreover, the signaling pathways in human valve disease are under intense investigation $[3,4,6,7,9,10]$. Understanding the parallel role of bone in the heart is becoming increasingly important since the phenotype of calcification in the valve has been identified as an osteogenic process [3]. The first study of valves and femurs was done using a model of renal failure [11] and it indicated that, in experimental renal failure, the valve is calcified while the bone loses mineral content. Recently, a similar effect in the valve and the bone was shown using molecular imaging in an $\mathrm{eNOS}^{-/-}$mouse model of experimental hypercholesterolemia [12]. 
In the current study, $\mathrm{LDLR}^{-/-}$mice showed similar findings using histomorphometric measurements and micro-CT; as the valves calcified, the bones developed decrease mineralization in the presence of an elevated-cholesterol diet. This study also demonstrates that calcein incorporation in valves and bones from the hypercholesterolemic model indicates an active process of bone turnover. The micro-CT results demonstrate that as the valves mineralize, the bones develop less mineralization. These histologic findings demonstrate the potential atherosclerotic connection between these two disease processes, which includes cellular activation, lipid accumulation, calcein incorporation, and changes in the mineralization process simultaneously in the two different target organs as shown in figure 3 . The presence of elevated cholesterol induces inflammatory cells to infiltrate and activate the classical histologic findings of atherosclerosis in the heart valve. In the femur, the decrease in bone formation as evidenced by micro-CT, the active bone turnover, and the presence of osteoclast cells indicate a parallel process in this organ. As the mineralization process is increased in the heart, it is decreased in the femurs, which chronically leads to a progressive decrease in bone thickness and over time potential osteoporotic changes simultaneously causing AVA stenosis. Treatment with the HMG-CoA reductase agent further confirms the importance of the cholesterol pathway in this disease model.

Clinical studies in the field of statins and AVA disease have demonstrated negative results in the randomized studies of SALTIRE [13], ASTRONOMER [14], and SEAS [15]. RAAVE [16] demonstrated in a hypothesisdriven study that aggressive LDL-lowering therapy slowed the progression of calcific AVA disease. Further studies in this field are necessary to characterize these cellular processes to further confirm this hypothesis. In conclusion, these findings provide a foundation for studying the role of bone formation in the heart and the effects on femurs in experimental hypercholesterolemia.

\section{Acknowledgements}

This work was completed with the support of 5R01HL085591 and 3R01HL085591S1. The author is the inventor on a patent for methods to slow the progression of valvular heart disease. The Mayo Clinic owns this patent and the author does not receive any royalties from this patent.

\section{References}

1 Figueiredo CP, Rajamannan NM, Lopes JB, Caparbo VF, Takayama L, Kuroishi ME, Oliveira IS, Menezes PR, Scazufca M, Bonfa E, Pereira RM: Serum phosphate and hip bone mineral density as additional factors for high vascular calcification scores in a communitydwelling: the Sao Paulo Ageing \& Health Study (SPAH). Bone 2013;52:354-359.

2 Chau DL, Edelman SV, Chandran M: Osteoporosis and diabetes. Curr Diab Rep 2003;3: $37-42$.

3 Rajamannan NM, Subramaniam M, Rickard D, Stock SR, Donovan J, Springett M, Orszulak T, Fullerton DA, Tajik AJ, Bonow RO, Spelsberg T: Human aortic valve calcification is associated with an osteoblast phenotype. Circulation 2003;107:2181-2184.

4 Caira FC, Stock SR, Gleason TG, McGee EC, Huang J, Bonow RO, Spelsberg TC, McCarthy PM, Rahimtoola SH, Rajamannan NM: Human degenerative valve disease is associated with up-regulation of low-density lipoprotein receptor-related protein 5 receptormediated bone formation. J Am Coll Cardiol 2006;47:1707-1712.

5 Rajamannan NM, Subramaniam M, Caira F, Stock SR, Spelsberg TC: Atorvastatin inhibits hypercholesterolemia-induced calcification in the aortic valves via the Lrp5 receptor pathway. Circulation 2005;112:I229-I234.
6 Rajamannan NM: The role of Lrp5/6 in cardiac valve disease: experimental hypercholesterolemia in the Apoe-/-/Lrp5-/- mice. J Cell Biochem 2011;112:2987-2991.

7 Rajamannan NM: The role of Lrp5/6 in cardiac valve disease: LDL-density-pressure theory. J Cell Biochem 2011;112:2222-2229.

8 Rajamannan NM, Evans FJ, Aikawa E, Grande-Allen KJ, Demer LL, Heistad DD, Simmons CA, Masters KS, Mathieu P, O’Brien KD, Schoen FJ, Towler DA, Yoganathan AP, Otto CM: Calcific aortic valve disease: not simply a degenerative process - a review and agenda for research from the national heart and lung and blood institute aortic stenosis working group. Executive summary: calcific aortic valve disease - 2011 update. Circulation 2011;124:1783-1791.

9 Rajamannan NM: Mechanisms of aortic valve calcification: the LDL-density-radius theory - a translation from cell signaling to physiology. Am J Physiol Heart Circ Physiol 2010; 298:H5-H15, in press.

10 Rajamannan NM: Bicuspid aortic valve disease: the role of oxidative stress in Lrp5 bone formation. Cardiovasc Pathol 2011;20:168-176.

11 Hjortnaes J, Butcher J, Figueiredo JL, Riccio M, Kohler RH, Kozloff KM, Weissleder R, Aikawa E: Arterial and aortic valve calcification inversely correlates with osteoporotic bone remodelling: a role for inflammation. Eur Heart J 2010;31:1975-1984.

12 Rajamannan NM: Oxidative-mechanical stress signals stem cell niche mediated Lrp5 osteogenesis in eNOS(-/-) null mice. J Cell Biochem 2012;113:1623-1634.

13 Cowell SJ, Newby DE, Prescott RJ, Bloomfield P, Reid J, Northridge DB, Boon NA: A randomized trial of intensive lipid-lowering therapy in calcific aortic stenosis. N Engl J Med 2005;352:2389-2397.

14 Chan KL, Teo K, Dumesnil JG, Ni A, Tam J: Effect of lipid lowering with rosuvastatin on progression of aortic stenosis: results of the aortic stenosis progression observation measuring effects of rosuvastatin (ASTRONOMER) trial. Circulation 2010;121:306-314.

15 Rossebo AB, Pedersen TR, Boman K, Brudi P, Chambers JB, Egstrup K, Gerdts E, GohlkeBarwolf C, Holme I, Kesaniemi YA, Malbecd W, Nienaber CA, Ray S, Skjaerpe T, Wachtell $\mathrm{K}$, Willenheimer R: Intensive lipid lowering with simvastatin and ezetimibe in aortic stenosis. N Engl J Med 2008;359:1343-1356.

16 Moura LM, Ramos SF, Zamorano JL, Barros IM, Azevedo LF, Rocha-Goncalves F, Rajamannan NM: Rosuvastatin affecting aortic valve endothelium to slow the progression of aortic stenosis. J Am Coll Cardiol 2007;49: 554-561. 